\title{
Cretaceous braconid wasps from the Magadan Province of Russia
}

\author{
Sergey A. Belokobylskij \\ Acta Palaeontologica Polonica 57 (2), 2012: 351-361 doi: http://dx.doi.org/10.4202/app.2010.0120
}

The Cretaceous genera of the hymenopteran family Braconidae are discussed. Overall, eight braconid subfamilies, including two only known from this period, and 17 genera together with two having unclear subfamily position, have been recorded in Cretaceous period. Two new genera, Magadanobracon gen. nov. (with two species, Magadanobracon rasnitsyni sp. nov. and M. zherikhini sp. nov.) and Cretorhyssalus gen. nov. (with type species Cretorhyssalus brevis sp. nov.) are described. The discussed position of the new genera in Protorhyssalinae remains putative owing to a lack of information about multiporous sensillae of the antenna and the poor preservation of the basal half of the hind wing. The earliest recorded thickened hind tibia in the female sex, as a probable apomorphic character of the subfamily Protorhyssalinae, and the evolutionary state of the antefurcal vs. postfurcal positions of the recurrent vein in the fore wing of Braconidae are discussed.

Key words: Insecta, Hymenoptera, Braconidae, Protorhyssalinae, parasitoids, ambers, prints, Cretaceous, Russia.

Sergey A. Belokobylskij [doryctes@yahoo.com], Museum and Institute of Zoology Polish Academy of Sciences, Wilcza 64, Warszawa 00-679, Poland.

This is an open-access article distributed under the terms of the Creative Commons Attribution License (for details please see creativecommons.org), which permits unrestricted use, distribution, and reproduction in any medium, provided the original author and source are credited. 
